\title{
Convergence in Media Education Curricula
}

\author{
M Karmasin*, S Diehl**, I Koinig** \\ * Austrian Academy of Science, Austria \\ ** Alpen-Adria-Universität Klagenfurt, Austria
}

\begin{abstract}
The paper intends to investigate current university degree programs in numerous European countries and compare them with offerings in the United States with regard to their suitability to contemporary workplace requirements in the age of convergence. Recent trends in convergence, defined as the merging and growing together of previously distinct industrial branches, professions, devices and skills (Jenkins, 2008) have changed and dramatically transformed the ways people communicate as well as interact with each another. As a consequence, academic and professional representatives are asked to respond to these far-reaching alterations in varying ways.

By use of an extensive content analysis, our study intends to analyze to which degree universities in Europe and the United States have started to already offer adequate programs on different educational levels (Bachelor, Master and $\mathrm{PhD}$ ) in an attempt to provide the kind of media education needed today and in the future. The paper takes a closer look at educational trainings and degree programs offered by post-secondary institutions throughout the world, scrutinizing whether convergence and related terms such as multimedia and cross-media have already managed to gain an (academic) foothold yet.
\end{abstract}

Keywords: convergence, education, cross-media, multimedia, university curricula, international comparison

\section{Introduction}

Media occupy a powerful role in present-day society. Besides transporting messages, they shape current opinions and allow for user participation, empowering numerous parties, such as producers, consumers etc. Empowerment is especially brought about on grounds of the increasing number of vehicles - digital and traditional, which is conditioned by trends of convergence (Perez Tornero et al., 2008). Hence, over the past years, convergence has risen and continued to affect the domains of both people's personal and professional lives. In a narrow sense, convergence refers to "complex, multi-layered interactions between 'traditional' (or 'old') communication cultures and emerging ('new') online, mobile media” (Allan, 2010, p.: xiivf.). In a broader sense, blurring boundaries are characteristic of present-day interactions and environments, thus, changing technological devices, workplace settings, industrial co-operations as well as communicative encounters and exchanges. Convergence, therefore, needs to be perceived as "a phenomenon resulting from the overlapping and merging of different media forms and functions that once operated separately” (Diehl et al., 2013, p. 354). The elimination of formerly distinct industrial sectors, job profiles and competencies, as well as the merging of private and occupational matters pose new challenges to educational institutions that need to be tackled in time to ensure companies' survival and lasting success in a globalized and connected world. Following recent claims, new media competencies and forms of literacy need to be addressed and emphasized in media education programs order to provide future staff with appropriate competencies to manage present and future challenges, familiarizing them with the tools and skills that might become of uttermost importance to corporate success (Arnolds-Granlund \& Kotilainen, 2010). 


\section{Convergence}

In general, convergence is perceived as a phenomenon resulting from the merging and overlapping of different media functions and forms which once operated separately and independently (Diehl et al., 2013). It can take numerous forms and primarily concerns media, businesses/industries, technologies and content. (1) Convergence of media recognizes the merging of previously independent devices and technologies, leading to the emergence of new services such as mobile TV, mobile Internet, Internet TV, Internet radio or "connected TV". (2) Convergence of businesses suggests that firms and industries formerly operating in different economic areas choose to cooperate and collaborate by (partially) leaving their original fields of expertise. Thereby, cross-functional operations are characterized by varying degrees of duration, intensity, and objectives. (3) Convergence of technologies, with its prime examples being Unified Messaging (UM) as well as Unified Communications (UC), collects and incorporates different communication forms (e.g., e-mails, text or fax messages) into one common ("unified") form that can be accessed as well as processed by a variety of devices (e.g. smartphones or e-mail clients) independent of their actual location. (4) Convergence of content postulates media content being not only used in different media channels and at multiple times, but also its adaptation to different media environments and their requirements respectively (Diehl et al., 2013); this is the case with news is being published on different platforms, such as the Internet or on TV and the radio (Karmasin \& Winter, 2000). Thereby, convergence is conditioned by the "three C's of convergent media, [namely] computing and information technology (IT), communications networks and digitized content” (Flew, 2008, p. 2). Yet, limiting convergence to the media realm is by far too simplistic since it has implications for other (related) domains as well and as such, convergence "is a word that manages to describe technological, industrial, cultural, and social changes depending on who [is] speaking and what they think they are talking about” (Jenkins, 2008, p. 3).

\section{Convergence’s Increasing Relevance}

For Dennis (2003), convergence does not cover changes in technical/technological services and platforms, business models and/or legal regulations alone; he claims that it is, first and foremost, a process „blurring the lines between media“ (Pool, 1983, p.: 24). However, it is not only limited to the media realm but recent trends of convergence (e.g., market deregulation tendencies, globalization, technical as well as technological innovation and altered customer expectations; Rhodes et al., 2006) exercise an impact on other disciplines as well.

Convergence and the Media: Convergence has had a drastic impact on the media and communication landscape, where it is perceived as an ongoing process in the course of which new technologies are integrated into existing ones. The media industry has been hit by convergence to the largest extent and in a two-fold manner: on the one hand, the sector has experienced an over-expositional increase in communication channels, conditioned by the rapid rise of the Internet and Internet-related technologies; on the other hand, convergence has managed to gain ground by eliminating previously established sectorial boundaries (Tambini, 2001). As a result, the media sector has to face new challenges quite similar to those of the IT industry (Noam, 2009). Thereby, changes predominantly concern the sector's major agents 
(McPhillips and \& Merlo, 2008), namely media owners as well as consumers, who are given the chance to use multiple services without changing platforms or devices respectively, and can use the same service on a variety of devices (Ofcom, 2008).

Convergence and the Business Environment: Technical innovations and technological advancements lead to new working environments, specifically in the areas of production and distribution, also affecting consumption. At the same time, sectorial convergence is taking place, which is to be understood as "a 'blurring' of boundaries between industries, induced by converging value propositions, technologies and markets that lead to the emergence of inter-industry segments" (Bröring et al., 2006, p.: 487). Through the convergence of industries new (convergent) products and services emerge; they do, however, not present novel inventions per se but instead presuppose the creation of innovative business models and more flexible organizational structures (Schwarz and \& Gustafsson, 2013). Convergence devices, such as smartphones or tablets are responsible for newly emerging competencies repeatedly uttered by enterprises, who expect their (prospective) job candidates not only to multi-task, but also to possess knowledge in different areas (Zorn, 2011). Predominantly, these skills concern dealing with more flexible working environments, technological knowledge, short-term team structures as well as intercultural competencies (Diehl et al., 2013). Business owners and managers alike are asked to ensure that work is done properly and in time, albeit staff is dividing their work between their home and their actual office workplace. The divided notion of the workplace has also been fostered through technological advancements (such as Cloud Services and Unified Communication Systems) which do not only support but also facilitate the exchange of data independent of people's locations. The use of these services also requires both new skills and a new form of media literacy to be successfully managed, and must be addressed in education.

Convergence and the Customer: In addition, media consumption has been drastically changed. For reasons of content convergence, media offerings are used multiple times, courting consumers along a variety of platforms. Technological infrastructures, especially communication technologies, experience a rapid growth which is mirrored by rising broad band Internet usage rates and an increasing dissemination in mobile communication devices (International Delphi Study, 2009). As a result, technical background knowledge becomes inevitable for users and (digital) consumers in order to ease their navigation (Zorn, 2011; Roth-Ebner, 2012). On grounds of this characteristic, users are enabled and encouraged to contribute online, transform and edit (digital) media content (Zorn, 2011), whereby the Internet - characterized by a high degree of participation - is the source driving change to unknown dimensions (Roth-Ebner, 2012). New age-media consumers are migratory and socially active, and publically connected (Jenkins, 2008) - all because of trends of convergence.

Convergent Journalism: Technical and technological convergence have changed the journalistic profession as its core, with news consumption having not remained the same either, for present-day consumers receive and respond (share and contribute) to news differently than only a few years ago (Erdal, 2007). In the professional domain, convergence journalism describes "some combination of technologies, products, staffs and geography amongst the previously distinct provinces of print, television and online media” (Singer, 2004, p.: 3). As a precondition for cross-media work, these trends foster dramatic changes across newsrooms, with agencies following multichannel strategies, multiplatform publishing and cross-media reporting 
(Kaltenbrunner and \& Meier, 2013). Today, news coverage has to happen quicker, at a more regular pace and simultaneously across platforms; therefore, management practices in content providing agencies have to be rethought and innovative news formats (e.g. cross-media storytelling, convergent platforms etc.) have originated in response to public pressure for exiting and unique content preparation.

All these trends discussed before lead to fractured notions of work and, as such, make the work process less predictable and controllable. As a result, it can be said that competencies do not exist by themselves but also converge, possibly bringing to mind the term "convergence of competencies". And since convergence is a trend playing into a variety of disciplines with diverse effects, these need to be (at least, partially) borne in mind by media education, which is called upon to provide suitable and tailored degree programs in order to educate the workforce of the future.

\section{Methods}

By the use of an extensive content analysis, our study sets out to analyze whether universities in selected European countries (Germany, Austria, Switzerland, Slovenia, Ireland, Great Britain, Scotland and Wales) and the United States are already responding to the new requirements of convergence by offering degree programs which provide the kind of media education needed today and in the future. Countries were selected if they offered a study portal which aided (prospective) candidates in their search for suitable educational programs. The present paper takes a closer look at educational offerings (Bachelor, Master, Diploma and $\mathrm{PhD}$ degree programs) provided by post-secondary educational institutions, scrutinizing whether convergence has already been able to gain an (academic) foothold yet. As convergence concerns numerous areas, such as media communications, journalism as

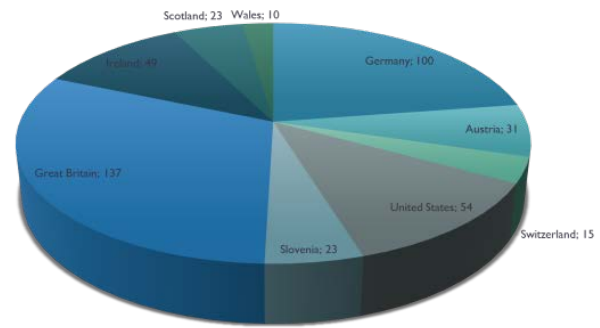

Figure 1: Number of Programs by Country $(n=443)$ well as economics, management and technical sciences, programs from these diverse backgrounds will be consulted.

For the present study, 443 different degree programs from six counties (for scores, see Figure 1) were analyzed in detail over a period of two months (July and August 2013: Germany, Austria, Switzerland, and the U.S. and/or February and March 2014: Slovenia, Ireland, Great Britain, Scotland, and Wales) for the purpose of revealing their focus on convergence and related fields. Hence, a detailed Internet analysis was conducted, whereby programs offered at the time of survey (2013/14) were investigated. In order to get a good overview about the programs offered, well-renowned study portals ${ }^{1}$ were consulted when available, with the exception of the U.S., where a plain Google search was conducted.

1 Austria: www.studieren.at; Germany: www.studieren.de; Switzerland: www.studium-schweiz.ch; Slovenia: http://www.studij.si/; Ireland: http://www.educationinireland.com/en/What-can-I-study-/; Scotland: Www.scottland.org/study-in-scottland; Wales: http://www.wales.com/en/content/cms/english/study/wales_universities/wales_universities.aspx; Great Britain: www.educationuk.org and www.studybritain.com. 


\section{Results}

Most degree programs are offered by universities (both private and public; $67.3 \%$ ) followed by universities of applied sciences (15.8\%) as well as colleges and/or academies (16.9\%). In terms of program type, Bachelor (54.6 \%) and Master (38.8 $\%)$ degrees clearly outnumber other educational trainings (like preparation classes or colleges), which constitute the smallest proportion (6.6 \%). In countries where English does not present an official language, a clear trend towards bilingual programs can be noted; in total, English is featured in 297 (67\%) of all cases, alluding to how globalization and convergent markets have altered present-day workplace settings by attributing a higher degree of importance to (foreign) language proficiency and raising English to the world's common language. Programs currently offered only in the country's national language take a backseat (with the exception of Slovenia, where programs are exclusively taught in Slovenian); they might be even doomed unsuitable in the long run and, if demand increases, it would be wise to adapt them accordingly. Yet, even though convergence is said to dismantle fixed working structures and makes them more flexible, this trend is not mirrored in the programs' design, for most programs are still full-time. By contrast, part-time degrees would enable students to get more used to current workplace settings and conditions, further enabling them to pursue a part time job in form of an internship, which would then allow them to put the knowledge acquired into practice.

Counting occurrences of the word convergence alone would proof to be insufficient; hence, two related concepts - namely cross media and multimedia - will be additionally used in this paper to achieve meaningful results. While convergence has already been defined extensively, cross media and multimedia still need to be conceptualized briefly in order to justify their selection for analysis. While cross media means all communicative efforts involving more than one media channel (Cambridge Dictionary, 2013a), multimedia refers to "communicating or sharing information in the form of sound, pictures, and video as well as text" (Cambridge Dictionary, 2013b). Since some overlapping between the definitions of convergence (especially between the definitions of convergence of media and content) can be found, the terms were regarded suitable for inclusion in the present study.

Table 1: Example of Term Occurrence ('Convergence') by Place of Listing

\begin{tabular}{|l|l|l|}
\hline \multicolumn{1}{|c|}{ Use of 'Convergence' Category } & \multicolumn{1}{c|}{ University } \\
\hline Media and Convergence Management & Study Title & $\begin{array}{l}\text { Alpen-Adria-University Klagenfurt, } \\
\text { Austria }\end{array}$ \\
\hline $\begin{array}{l}\text { Convergence Journalism } \\
\begin{array}{l}\text { Integrating Media: Convergence in } \\
\text { Practice (4) }\end{array}\end{array}$ & Study Title & $\begin{array}{l}\text { University of Missouri, United } \\
\text { States }\end{array}$ \\
\hline $\begin{array}{l}\text { Cross-media journalism and journalism in Content } \\
\text { convergent media }\end{array}$ & Module & $\begin{array}{l}\text { Penn State University, United States } \\
\text { Kommunikation und Wirtschaft, } \\
\text { Berlin, Germany }\end{array}$ \\
\hline $\begin{array}{l}\text { Media Literacy/Education - audiovisual } \\
\text { culture and communication }\end{array}$ & Module & $\begin{array}{l}\text { Otto von Guericke - University of } \\
\text { Magdeburg }\end{array}$ \\
\hline $\begin{array}{l}\text { Culture and Media Education } \\
\text { University of } \\
\text { Ludwigshafen }\end{array}$ \\
\hline
\end{tabular}

Out of 443 degree program offerings, 215 (38\%) mention the term convergence (C) in one way or another; cross-media (CM) is included in relatively few instances (53/9 
\%), while multimedia (MM) is most frequently included (301/53 \%). Rare occurrences of all terms are found for the usage in the actual program title (C: $7 \%$ /CM: $6 \%$ /MM: $12 \%$ ), while it is slightly more commonly utilized as a module title (C: $20 \%$ /CM: $20 \%$ /MM: $35 \%$ ); most occurrences can be noted as module content (C: $73 \%$ /CM: $74 \%$ /MM: $53 \%$ ). For example occurrences, see Table 1. In the modules containing the key terms as module content, the terms' mention predominantly concerns course content (261/58.9\%) and in fewer cases an actual course title (156/35.2\%). As to place of mention, multiple occurrences can be noted (in order of cases): in the program description (C: 57 \% /CM: $41 \%$ /MM: $69 \%$ ), in the course of study (C: $25 \%$ /CM: $39 \%$ /MM: $19 \%$ ), in the course offerings (C: 13 \% /CM: 11 \% /MM: $11 \%$ ) and in the degree program's curriculum (C: 5 \% /CM: $9 \%$ /MM: $1 \%)$.

In general, definitions of the term convergence are missing and are given in less than $1 \%$ of all results; hence, determining the degree program's focus is a rather complicated matter. Therefore, content was scrutinized in more detail, especially with regard to its relation to different fields of study, which are said to converge in presentday (workplace) environments. While a clear focus on media and communication sciences was immanent to all programs, only $27 \%$ of all programs solely put their focus on communication theories. Rather, they have started to broaden their horizon to other disciplines for input by taking up theories from other scientific backgrounds to varying degrees: journalism (29\%), economics and management (4\%) and technical sciences (15\%) respectively. Programs with interdisciplinary focus are, thus, starting to gain ground, accounting for already $20 \%$.

Additionally, education seems not to be solely theoretical anymore, for already $44 \%$ of the programs scrutinized offer practical courses paired with theoretical input. Yet, purely practical classes alone hardly exist (1\%). This indicates that applied classes, in which knowledge is utilized in a practical setting, are becoming increasingly relevant. They are usually to be found in the area of journalism (in form of cross-media and multimedia classes), where a balance between theoretical and practical teaching formats is achieved. As far as these new trends are integrated into the complete program, most degree offerings either assign a single class (63\%) or a module (two or more classes; $29 \%$ ) to this particular topic, while others (very few, though) even dedicate the complete degree program (8\%) towards this newly emerging area.

\section{Discussion of Results, Recommendations and Future Outlook}

Present study results clearly indicate that convergence and related concepts have started to increase in relevance in the media education realm throughout Europe and in the United States. Of all the terms scrutinized, multimedia is most commonly used ( $\sim 53 \%$ ), followed by convergence $(\sim 38 \%$ ) and crossmedia $(\sim 9 \%)$. Within those programs, all terms are used to almost equal parts as module content ( $65 \%$ ), module titles ( $\sim 20 \%)$, with study titles ranking last $(\sim 7 \%)$. Yet, some countryspecific differences are noteworthy: while in all countries the terms are mostly applied as module content, they are more often used as study titles in the U.S. (24 \%), which could indicate the increased importance attributed to this specialization overseas. In terms of the degree programs' foci, a clear tendency towards the area of communication surfaces as all programs can be clearly traced back to their media studies' origins. While some programs still focus on media and communication topics alone (27\%), they are almost equal up with programs stressing journalistic topics (29 
$\%)$. The second place, however, is already assigned to programs with interdisciplinary focus (20\%), combining media elements with concepts taken from economic and management as well as technical sciences. These disciplines are practiced to a smaller degree in their pure forms but are of benefit to the area of research as convergence is based on technical developments and changing numerous professions at their core: 15 $\%$ technical sciences, as well as $4 \%$ economics and management. The extent to which convergence is taught at universities, seems to be indicative of these results as well. Predominantly (in $63 \%$ of all cases), single classes are dedicated towards this subject area, whereas one module (defined as consisting of two or more classes) can be found in second place (29\%). Full degree programs account for $8 \%$.

Amongst practitioners and academics, the term convergence has become used "as a rhetorical toll in order to facilitate reform, [with the] media landscape undergoing significant change" (Fagerjord and Storsul, 2007: 28). As a consequence, the academic landscape has to change as well to allow for integrated program solutions: it is universities' educational duty to provide appropriate means in form of tailored educational trainings that take present-day and future challenges into account. This means that they must not only (exclusively) center on media convergence but should also pay tribute to other trends and social developments (e.g., the transformation from an information society to a knowledge society), globalization as well as altered political and legal regulations. The present study has demonstrated quite plainly that missing definitions of the core terms impede determining the subject area's exact focus. Yet, these should be included for definitions are meant to provide some guidance and/or orientation on what to expect of the actual program. Additionally, the extent and amount of information available on each program differs considerably; therefore, information should be presented in a unified way and cohesive structure.

Trends of convergence are meant to change the educational landscape forever. Yet, the above elaboration is far from being complete as technologies and competencies pointed out in this text solely fit current requirements, but since changes are often unpredicted, surprising and faster than ever imagined this paper does neither present permanent solutions nor fixed answers. Rather, it tried to draw attention to already identified trends, which indicate that convergence increasingly dissolves academic boundaries. And as such, it also needs to be mirrored in future media education programs.

\section{References}

Allan, S. (2010). Series Editor's Foreword. In T. Dwyer (ed.). Media Convergence. Maidenhead: Open University Press. xiii-xiv.

Arnolds-Granlund, S.B.; \& Kotilainen, S. (2010). Media Literacy Education: Nordic Perspectives. Gothenborg: Nordicom.

Bröring, S.; Coultier, L.M.; \& Leker, J. (2006). The front end of innovation in an era of industry convergence. $R \& D$ Management. 36(5). 487-498.

Cambridge Dictionary. (2013a). Cross-media. Retrieved 25 September 2013 from http://dictionary.cambridge.org/dictionary/british/multimedia

Cambridge Dictionary. (2013b). Multimedia. Retrieved 25 September 2013 from http://dictionary.cambridge.org/dictionary/business-english/cross-media

Dennis, E.E. (2003). Prospects for a big idea - Is there a future for convergence? The International Journal on Media Management. 5. 7-11. 
Diehl, S.; Karmasin, M.; Leopold, A.; Koinig, I. (2013). New Competencies for the Future. In S. Diehl \& M. Karmasin (eds.). Media and Convergence Management. (pp. 355-378). Berlin, Heidelberg: Springer.

Erdal, I.J. (2007). Researching Media Convergence and Crossmedia News Production: Mapping the field. Nordicom Review. 28(2). 51-61.

Fagerjord, A. \& Storsul, T. (2007). Questioning convergence. In T. Storsul \& D. Suedahl (eds.). Ambivalence towards convergence: digitalization and media change. Göteborg University: Nordicom.

Flew, T. (2008). New Media: An Introduction. $3^{\text {rd }}$ edition. Oxford: Oxford University Press.

International Delphi Study. (2009). Zukunft und Zukunftsfähigkeit der Informationsund Kommunikationstechnologien und Medien. Retrieved 2 May 2013 from http://www.tnsinfratest.com/presse/pdf/Zukunft_IKT/Zukunft_und_Zukunftsfaeh igkeit_der_IKT 2009.pdf

Jenkins, H. (2008). Convergence Culture: Where Old and New Media Collide. $2^{\text {nd }}$ ed. New York, London: New York University Press.

Kaltenbrunner, A. \& Meier, K. (2013). Convergent Journalism - Newsroom, Routines, Job Profiles and Training. In S. Diehl and M. Karmasin (eds.). Media and Convergence Management. (pp. 285-298). Berlin, Heidelberg: Springer.

Karmasin, M. \& Winter, C. (eds.) (2000). Grundlagen des Medienmanagements. Munich: UTB.

McPhillips, S. \& Merlo, O. (2008). Media convergence and the evolving media business model. The Marketing Review. 8(3). 3. 237-253.

Noam, E.M. (2009). Media ownership and concentration in America. Oxford: Oxford University Press.

Ofcom, (2008). The International Communications Market 2008. Convergence. December. London: Ofcom.

Perez Tornero, J.M.; Jacquinot-Delaunay, G.; Tayie, S.; \& Carlsson, U. (2008). Empowerment Through Media Education. Gothenborg: Nordicom.

Pool, I.d.S. (1983). Technologies of Freedom. Cambridge, MA: Harvard University Press

Rhodes, J., Walsh, P. \& Lok, P. (2006). Convergence and Divergence Issues in Strategic Management. Retrieved 26 August 2013 from http://w3.unisa.edu.au/igsb/docs/wp-lok1.pdf

Roth-Ebner, C. (2012). Medienkompetenz und Genderkompetenz. Retrieved 17 July 2013 from http://www.medienimpulse.at/articles/view/352

Schwarz, E. \& Gustafsson, V. (2013). Business Modelling and Convergence. In S. Diehl and M. Karmasin (eds.). Media and Convergence Management. (pp. 9-24). Berlin, Heidelberg: Springer.

Singer, J. (2004). Strange Bedfellows? The Diffusion of Convergence in Four News Organizations. Journalism Studies. 5(1). 3-18.

Tambini, D. (2001). Revolution, Communication and Reform. London: Institute for Public Policy Research.

Zorn, I. (2011). Medienkompetenz und Medienbildung mit Fokus auf Digitale Medien. In H. Moser; P. Grell \& H. Niesyto (eds.). Medienbildung und Medienkompetenz. (pp. 175-209). Munich: Kopaed. 